\title{
Design and Usability Evaluation of Communication Board for Deaf People with User-Centered Design Approach
}

\author{
https://doi.org/10.3991/ijim.v12i2.8100 \\ Rizdania Dermawi( $\left.{ }^{(}\right)$, Herman Tolle, Ismiarta Aknuranda \\ Universitas Brawijaya, Malang, Indonesia \\ rizdaniadermawi@gmail.com
}

\begin{abstract}
People interacts their environment by communicating, but some limitation may exist such as hearing disability that occurs to deaf people. Usually, they communicate by using sign language. Unfortunately, there is various sign language in the world. This research is evaluating the usability of smartphone for communication board that can be used by deaf people to communicate to others, especially the people who don't understand the sign language. Usability testing is to measure the user performance for mobile applications. The five criteria for the usability, according to Nielsen are learnability, efficiency, memorability, errors, and satisfaction. The study obtained the result of $88.36 \%$ of usability testing.
\end{abstract}

Keywords—communication board, usability, user-centered design, deaf people

\section{Introduction}

Communication is a human way of interacting with the surrounding environment. According to the American Speech-Language Hearing Associaton (ASHA), communication is any action taken by a person to provide or receive information for or from another person to express their needs, desires, perceptions, knowledge or statements [1]. But some people have hearing disabilities that may obstruct them to communicate with others. The World Health Organization (WHO) stated that more than 360 million people worldwide have disabling hearing loss. The cause of hearing loss and deafness are natural causes and acquired causes, such as diseases, ear infections, and aging [2]. Deaf people are unable to hear, and they also can't express their intention orally, so they communicate by using sign language [3]. But the sign language can only be understood by the person who has learned it, and many other ordinary human beings will have difficulty understanding the sign language [4]. It may cause the message from deaf people can't be accepted well, so the may need an alternative media that may help them to communicate with others.

After pre-observation on a deaf community in a city of East Java, Indonesia, and also by reading some literature, there some facts that can be categorized as the lacks of the sign language. The first is there is more than one kind of sign language. Some 
sign language for the particular word may change time to time. So for non-deaf people, it may be very hard to keep up the various vocabularies of sign language.

Smartphones nowadays are used by a lot of people and also by deaf people. A survey mentioned that more than fifty percent of deaf people are smartphone users [5]. They use the smartphone's applications that relate to chatting and video call because of their limitations [6]. To overcoming the problem of deaf people when they want to communicate to ordinary people, a solution is proposed. This research aims to evaluate the usability of the smartphone as the communication board which they can use for communicating with common people so that can be useful for deaf people. Some studies relate to communication board (CB) was the use of $\mathrm{CB}$ for a patient with a ventilator in the hospital [7], and also the study of alphabetical arrangement on $\mathrm{CB}$, so it eases the users [8].

\section{$2 \quad$ Materials and Methods}

To accommodate the needs of deaf people, the communication board has to be designed just like how they want it was. User experience is one way that is expected to meet the desire of the users. Garret stated in his book, user-centered design is when we involve users in every stage of application development. User experience is significant to the developers because it is the most important thing for the users as well [9].

When an application of a user-centered design approach is to be acknowledged, it had to be thoroughly prepared and designed all aspects of the system development process thoroughly. The process of user-centered design is composed of some critical activities that will be described in next section [10], [11].

\subsection{Understanding and Specify the Context of Use}

At the point a system or a product is created, it will be utilized in a specific setting. A client populace will utilize it with particular characteristics. They will have specific objectives and wish to perform a particular assignment. The product will likewise be utilized inside a specific scope of specialized, physical and social or other conditions that may influence its utilization [10].

\subsection{Understanding and Specify the User Requirement}

Requirements elicitation and investigation is broadly acknowledged to be an essential piece of software development. Without a doubt, the accomplishment of a software development program can build upon how well this process is completed. The way of gathering requirements is in this study by an interview the deaf people as the users to gain information about their needs or requirement about the new system. The interview is normally semistructured in light of a progression of settled inquiries with scope for the users to develop their reactions. A semi-structured interview is helpful in circumstances where wide issues might be seen, yet the scope of 
respondents' responses to these problems isn't completely discovered. The structured interview should ought just be completed in circumstances where the respondents' scope of answers is recognized, and there is a necessity to gage the quality of each shade of thinking. Interviewing can likewise be utilized as an aspect of task analysis [10].

User Requirements. User requirements will include summary descriptions of the tasks that the system will support and the functions that will be provided to support them. It will provide example task scenarios and possible interaction steps for the future system, and describe any features of the system to meet the context-of-use characteristics. The process of gathering the user requirements is very essential, so it guides to the phase of the particular system design. User requirements consist of arbitrary characterization of the assignment that will be given to help. It will give case undertaking situations and conceivable collaboration ventures for the future framework, and depict any highlights of the framework to meet the set of utilization qualities [9].

Usability Requirements. It is additionally essential to depict the itemized ease of use prerequisites with a specific end goal to set destinations for the outline group and help organize ease of use work. The general convenience objectives o characterize are the accompanying [12]:

1. Effectiveness: how the system or the product may help the user to fulfill their goal.

2. Efficiency: the time to finish errands.

3. Satisfaction: the convenience and users' opinion of the product.

\subsection{Iteration of Design Solutions}

The arrangements of the design emerge from numerous points of view, from replicating and development, through to imaginative inventiveness. Whatever the first source, all outlines thoughts as they advance will experience iterative improvement. Ridicule ups and reproduction of the framework are important to help this iterative plan lifecycle. At the least complex, they may comprise of a progression of UI screens, and a fractional database is enabling potential clients to associate with, imagine and remark on the future outline. Such reproductions or models can be created both rapidly and effortlessly in the beginning periods of the framework improvement cycle for assessment by human components specialists, client delegates and individuals from the planning group. Changes to the plan may then be made quickly in light of client criticism, so significant issues with the outline can be distinguished before framework improvement starts. This stays away from the expensive procedure of remedying configuration blames in the later phases of the development cycle [10].

\subsection{Evaluating the solutions with the users against requirements}

The designs ought to be assessed all through advancement, at first utilizing low constancy (ordinarily paper) models, took after later by more complex models. This is 
an imperative action inside the framework improvement lifecycle; it can affirm how far client and authoritative targets have been met and additionally give additional data to refining the plan. Similarly, as with the other, the activities of user-centered it is prudent to do assessments from the most punctual open door, before rolling out improvements turn out to be restrictively costly [10].

There are two main reasons for usability evaluation, which are [13]:

1. Formative Testing: to increase the product which is one of the developing phase (by identifying and fixing usability issues).

2. Summative Testing: to figure out that user may succeed in using the product.

The questionnaire given to the users is the way to collect their opinion regarding the product usage, how the product affects them, how the product may satisfy them. This can be accomplished with the utilization of questionnaire or through direct correspondence with the respondents.

\section{Result and Discussion}

\subsection{Understanding and Specify the Context of Use}

An observation as the survey of existing users shows that in Malang city exists some communities for deaf people. One of the community is chosen as the place of observation. The field study is the community in the Brawijaya University where the research can give the pre-questionnaire for determining the problems. Observational methods involved an investigator viewing users as they work and taking notes of the activity in the deaf people community.

\subsection{Understanding and Specify the User Requirement}

In this study, the researcher used a pre-questionnaire for gathering the background of the users. The questionnaire contains some questions and some fields that have to be filled by the deaf people related to their personal data, such as gender, age and education [10].

Table 1 shows the list of the questions given as the pre-questionnaire for the deaf people in the community to gather the user requirement.

There are open questions in the pre-questionnaire form because the research wants to dig the answers to the users and hopefully can be able to get the real story from the deaf people as the users. From the collected responses of the pre-questionnaire, the personas can be formed. Personas are a means of representing users' needs to design team, by creating caricatures to represent the most significant user groups. Each persona can be associated with one or more scenarios of use. Table 2 shows the persona formed to form the pre-questionnaire. 
Table 1. List of the questions in the pre-questionnaire form

\begin{tabular}{|c|l|}
\hline 1. & $\begin{array}{l}\text { What are the difficulties when communicating with new non-deaf people (who don't understand the } \\
\text { sign language? }\end{array}$ \\
\hline 2. & What are the topics you communicate to the non-deaf people for the first time you meet? \\
\hline 3. & Do you use Bahasa Indonesia grammar in everyday communication? \\
\hline 4. & $\begin{array}{l}\text { Would you be helpful if there was an application that may help you to communicate to non-deaf } \\
\text { people? Please give the reason. }\end{array}$ \\
\hline 5. & $\begin{array}{l}\text { Will you be cooperated to try the application of communication board for communicating to non- } \\
\text { deaf people? Please give the reason. }\end{array}$ \\
\hline
\end{tabular}

Table 2. The personas formed from the pre-questionnaire

\begin{tabular}{|c|c|c|}
\hline No. & Personal Data & Problem Description \\
\hline 1. & $\begin{array}{l}\text { User No. } 1 \\
\text { Age: } 25 \text { years old } \\
\text { Sex: Female } \\
\text { Education: college student major in } \\
\text { management }\end{array}$ & $\begin{array}{l}\text { - I have problem in communication because there are } \\
\text { many vocabularies that I don't understand } \\
\text { - I would be very enthusiastic if there were an application } \\
\text { that can help deaf people in communication }\end{array}$ \\
\hline 2. & \begin{tabular}{|l|} 
User No. 1 \\
Age: 20 years old \\
Sex: Female \\
Education: college student major in \\
agrotechnology
\end{tabular} & $\begin{array}{l}\text { - It is very hard if my friend talks to me too fast, so I } \\
\text { usually write what I want to say } \\
\text { - I hope there was an application that may help me } \\
\text { communicate to non-deaf }\end{array}$ \\
\hline 3. & $\begin{array}{l}\text { User No.3 } \\
\text { Age: } 22 \text { years old } \\
\text { Sex: Male } \\
\text { Education: college student major in } \\
\text { economics }\end{array}$ & $\begin{array}{l}\text { - I find it difficult to communicate to others because they } \\
\text { don't understand sign language. } \\
\text { - I would be very happy if there were an application to } \\
\text { help me in communication }\end{array}$ \\
\hline
\end{tabular}

From the personas achieved from the previous phase, this study gets some user requirement that can guide to the goal of the research. The requirements are as follows:

1. The communication board (CB) has to be able to provide the shortcuts that represent the sentences that usually used in everyday conversations.

2. The CB has to be able to play the voice of the sentences that have been chosen by the users.

\subsection{Iteration of Design Solutions}

In this phase, this study used the wireframe for the first design before it comes to the software prototyping. Fig. 1 shows the wireframe of the page of the planned application of communication board (CB).

The wireframe shows the app contains some shortcuts to represent the sentences that usually used in everyday conversation. So when the users want to say something to non-deaf people, the $\mathrm{CB}$ can be very helpful. The application contains some shortcuts of the sentences that are often used in everyday conversation when the deaf 
people meet new people. The sentences are divided into three sections, which are: greeting, introduction, and asking help.

After that, the design is then coded into the actual application or in prototype form. Fig. 2 shows the display in the prototype of the communication board (CB). The users can try the prototype by themselves and in the next phase of UCD process, the evaluation can be done by asking the users' opinion.

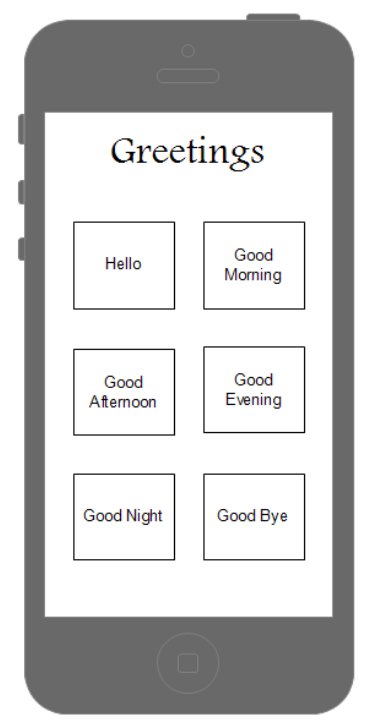

Fig. 1. The wireframe of the communication board (CB)

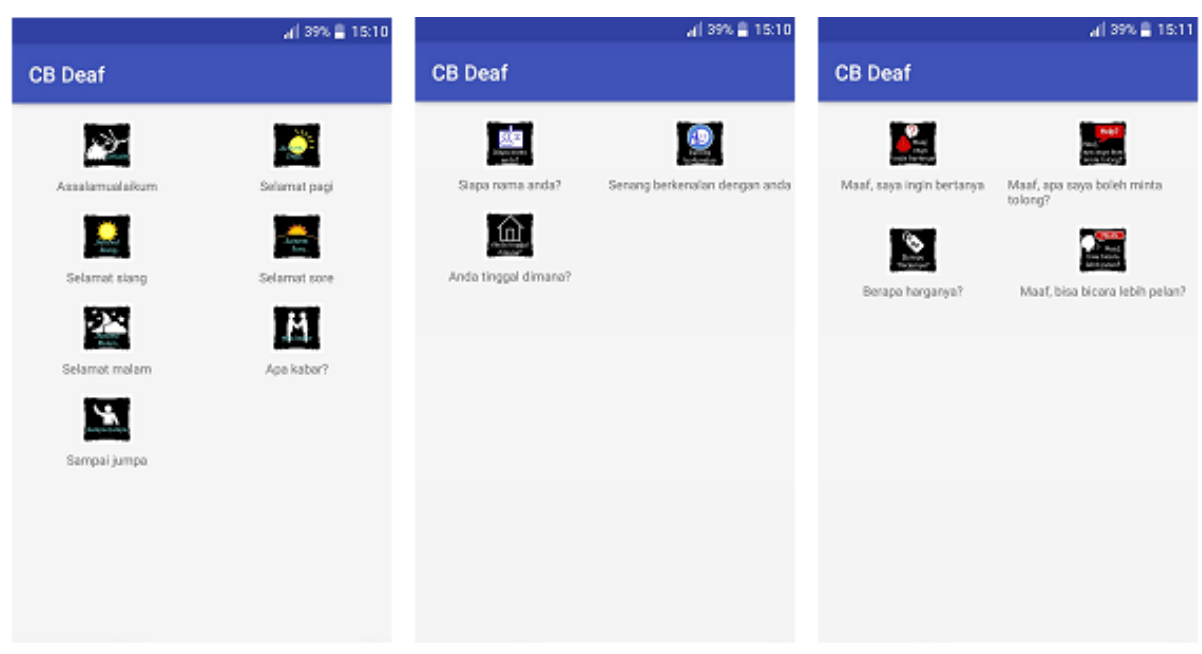

Fig. 2. The displays in the communication board (CB) prototype 


\subsection{Evaluating the solutions with the users against requirements}

Usability evaluation is an evaluation that is done to figure out the easiness of the system usage. This evaluation is by testing the developed system. Jakob Nielsen defined usability by five criteria, which are: Learnability, Efficiency, Memorability, Errors, and Satisfaction [14]. Some questions are prepared for the respondents' response. The Likert scale is used to obtain the result of the usability evaluation, so there are five scores that valued 1 to 5 . Table 3 shows the score of the answer of the questions. Table 4 shows the list of questions in the questionnaire and also the result.

There were five deaf users that given the questionnaires. They tried and tested the product of communication board for deaf people. The result gathered from the questionnaires is shown in Table 4.

Table 3. The score of the answers

\begin{tabular}{|c|c|}
\hline Score & Description \\
\hline 1 & Strongly Disagree \\
\hline 2 & Disagree \\
\hline 3 & Neutral \\
\hline 4 & Agree \\
\hline 5 & Strongly Agree \\
\hline
\end{tabular}

Table 4. Result of the questionnaire

\begin{tabular}{|c|c|c|c|c|c|c|c|}
\hline \multirow{2}{*}{ No. } & \multirow{2}{*}{ Questions } & \multicolumn{5}{|c|}{ Score } & \multirow{2}{*}{$\begin{array}{l}\text { Total } \\
\text { Score }\end{array}$} \\
\hline & & 1 & 2 & 3 & 4 & 5 & \\
\hline \multicolumn{8}{|c|}{ Learnability } \\
\hline 1. & $\begin{array}{l}\text { I think that the menu in the application are easy to be } \\
\text { recognized }\end{array}$ & 0 & 0 & 1 & 2 & 2 & 21 \\
\hline 2. & I think this application is easy to learn & 0 & 0 & 0 & 3 & 2 & 22 \\
\hline \multicolumn{8}{|c|}{ Efficiency } \\
\hline 3. & $\begin{array}{l}\text { I think that this application is helpful for me to communicate } \\
\text { to new friend }\end{array}$ & 0 & 0 & 0 & 2 & 3 & 23 \\
\hline 4. & I think this application help me to speak to non-deaf people & 0 & 0 & 2 & 1 & 2 & 20 \\
\hline 6. & I think this application has a feature that an easy to use & 0 & 0 & 0 & 2 & 3 & 23 \\
\hline \multicolumn{8}{|c|}{ Memorability } \\
\hline 7. & I think this application's feature very easy to memorize & 0 & 0 & 0 & 3 & 2 & 22 \\
\hline 8. & I think that this application is very easy to operate & 0 & 0 & 0 & 3 & 2 & 22 \\
\hline \multicolumn{8}{|c|}{$\begin{array}{ll}\text { Errors } \\
\end{array}$} \\
\hline 9. & I think I don't do mistakes when operating the application & 0 & 0 & 1 & 2 & 2 & 21 \\
\hline 10 & $\begin{array}{l}\text { I think if I make a mistake in the application, it is very easy } \\
\text { to repair it }\end{array}$ & 0 & 0 & 1 & 1 & 3 & 22 \\
\hline \multicolumn{8}{|c|}{ Satisfaction } \\
\hline 11. & I think it is comfortable to use this application & 0 & 0 & 0 & 1 & 4 & 24 \\
\hline 12. & I think this application is satisfying & 0 & 0 & 0 & 2 & 3 & 23 \\
\hline
\end{tabular}


The result obtained from the users were zero answers of "Strongly Disagree" and "Disagree", five answers of "Neutral", twenty-two answers of "Agree" and twentyeight answers of "Strongly Agree". Tabel 5 shows the value of each criterion in percentage.

The maximum value was obtained from the highest score of each criteria times the number of respondents in each category. Table 6 shows the calculation of usability in each category. From the usability testing, the average of the product usability is $88.46 \%$.

Table 5. The Result Value of each criterion

\begin{tabular}{|c|l|c|c|c|c|c|c|}
\hline No. & \multicolumn{1}{|c|}{ Criteria } & $\mathbf{1}$ & $\mathbf{2}$ & $\mathbf{3}$ & $\mathbf{4}$ & $\mathbf{5}$ & Total \\
\hline 1. & Learnability & $0 \times 1$ & $0 \times 2$ & $1 \times 3$ & $5 \times 4$ & $4 \times 5$ & 43 \\
\hline 2. & Efficiency & $0 \times 1$ & $0 \times 2$ & $2 \times 3$ & $5 \times 4$ & $8 \times 5$ & 66 \\
\hline 3. & Memorability & $0 \times 1$ & $0 \times 2$ & $0 \times 3$ & $6 \times 4$ & $4 \times 5$ & 44 \\
\hline 4. & Errors & $0 \times 1$ & $0 \times 2$ & $2 \times 3$ & $3 \times 4$ & $5 \times 5$ & 43 \\
\hline 5. & Satisfaction & $0 \times 1$ & $0 \times 2$ & $0 \times 3$ & $3 \times 4$ & $7 \times 5$ & 47 \\
\hline & TOTAL & $\mathbf{0} \times \mathbf{1}$ & $\mathbf{0} \times \mathbf{2}$ & $\mathbf{5} \times \mathbf{3}$ & $\mathbf{2 2} \times \mathbf{4}$ & $\mathbf{2 8} \times \mathbf{5}$ & $\mathbf{2 4 3}$ \\
\hline
\end{tabular}

Table 6. The Result of Usability in Each Category

\begin{tabular}{|c|c|c|c|c|}
\hline No. & Category & Total Score $\times$ Likert Score & Maximum Score & Result \\
\hline 1. & Learnability & 43 & 50 & $(43 / 50) \times 100 \%=86 \%$ \\
\hline 2. & Efficiency & 66 & 75 & $(66 / 75) \times 100 \%=88 \%$ \\
\hline 3. & Memorability & 44 & 50 & $(44 / 50) \times 100 \%=88 \%$ \\
\hline 4. & Errors & 43 & 50 & $(43 / 50) \times 100 \%=86 \%$ \\
\hline 5. & Satisfaction & 47 & 50 & $(47 / 50) \times 100 \%=94 \%$ \\
\hline & TOTAL & 243 & 275 & $\begin{array}{c}(243 / 275) \times 100 \%= \\
88.36 \%\end{array}$ \\
\hline
\end{tabular}

\section{Conclusion}

This study is about usability evaluation of communication board for deaf people with a user-centered design approach. The deaf people as the users were being involved in the four phases of the user-centered design development approach. The first phase was the figuring out the context of use, which was the process of determining the product and the user of the product as well. This research focused on a community of deaf in Brawijaya University, East Java, Indonesia. The second process was understanding and gaining the user requirement, which obtained the background data of the users, the personas listing and also the user requirements itself. The third process was making the design of the product. From the user requirements achieved before, this third phase was satisfying the users willing of overcoming their problems. To ensure that the design was properly made, the fourth phase was done by collecting the users' opinion from the questionnaires given. The result of the evaluation must at least $80 \%$ to fulfill the proper criteria. 
This accomplishment of usability product configuration requires some solutions:

1. Carefully arranging for the process of user-centered design.

2. Understand the context of use product as a reason for distinguishing requirements and evaluate the product.

3. Understand and specify the user requirements in a reasonable way which can be surveyed for accomplishment.

4. System and UI improvement in light of an adaptable and iterative approach.

5. Usability assessment is given both experienced and user testing at suitable focuses.

It is winding up progressively clear that usability using user-centered design is the way to future business accomplishment for the product being created. To guarantee an effective result, the team design must fulfill the requirements and needs of the user when for completed development. To accomplish this, the users of the products must be spoken to all through the procedure as the best choice for creating usable and effective items. According to the ISO 13407, the process executes a perfect system to guarantee full portrayal of the clients all through the product configuration process.

\section{$5 \quad$ References}

[1] W. O. Schalick, C. Westbrook, and B. Young, "Communication with Individuals with Intellectual Disabilities and Psychiatric Disabilities: A Summary of the Literature," Michigan Retire. Res. Cent. Res. Pap., pp. 1-49, 2012.

[2] WHO, "Deafness and Hearing Loss," World Health Organization, 2017. [Online]. Available: http://www.who.int/mediacentre/factsheets/fs300/en/. [Accessed: 04-Dec2017].

[3] J. Shang and J. Wu, "A Robust Sign Language Recognition System with Sparsely Labeled Instances Using Wi-Fi Signals," in 2017 IEEE International Conference on Mobile Ad Hoc and Sensor Systems, 2017, pp. 99-107. https://doi.org/10.1109/MASS.2017.41

[4] A. L. C. Barczak and F. Dadgostar, "Real-Time Hand Tracking Using a Set of Cooperative Classifiers Based on Haar-Like Features," Res.Lett. Inf. Math. Sci, vol. 7, pp. 29-42, 2005.

[5] Ofcom, "Disabled consumers' Use of Communications Services - A Consumer Experience Report," 2015.

[6] N. Narasimhan, A. Leblois, D. Bharthur, L. Haridas, P. Lal, P. Looms, R. Pathania, D. Prasad, S. Schorr, and M. Sharma, "Making Mobile Phones and services accessible for Persons with disabilities," 2012.

[7] L. Patak, A. Gawlinski, N. I. Fung, L. Doering, J. Berg, and E. A. Henneman, "Communication boards in critical care: patients' views," Appl. Nurs. Res., vol. 19, no. 4, pp. 182-190, 2006. https://doi.org/10.1016/j.apnr.2005.09.006

[8] D. J. Williams, "Evaluation and Design of Alphabetic Communication Boards," Appl. Math., vol. 7, no. 2, pp. 125-129, 2016. https://doi.org/10.4236/am.2016.72011

[9] J. J. Garrett, The Elements of User Experience: User-Centered Design for the Web and Beyond, 2nd Editio. Berkeley, CA: Pearson Education, 2011.

[10] M. Maguire, "Methods to support human-centred design," Int. J. Hum. Comput. Stud., vol. 55, pp. 587-634, 2001. https://doi.org/10.1006/ijhc.2001.0503

[11] N. Media, "User-Centred Design Guidelines for Methods and Tools," Finland, 2005.

[12] ISO-9241-11, “ISO 9241-11," 1998. 
[13] C. M. Barnum, Usability Testing Essentials. Burlington, MA: Elsevier, 2011.

[14] P. Tsai, “A SURVEY OF EMPIRICAL USABILITY EVALUATION METHODS,” 1996.

\section{Authors}

Rizdania is current as a Magister student in Faculty of Computer Science Brawijaya University, Malang, Indonesia. She is with the Research Group of Multimedia, Game and Mobile Technology, Informatics Department of Computer Science Faculty, Brawijaya University. (e-mail: rizdaniadermawi@gmail.com).

Herman Tolle is with the Research Group of Multimedia, Game \& Mobile Technology, Faculty of Computer Science, Brawijaya University, Malang, Indonesia. (e-mail: emang@ub.ac.id, herman.saga@gmail.com).

Ismiarta Aknuranda is with the Research Group of Information System, Faculty of Computer Science, Brawijaya University, Malang, INDONESIA (e-mail: i.aknuranda@ub.ac.id)

Article submitted 12 December 2017. Final acceptance 21 January 2018. Final version published as submitted by the authors. 